Abstract PM0-149 Table 1

\begin{tabular}{|c|c|c|c|c|c|c|c|}
\hline Patient & $\begin{array}{l}\text { Age } \\
\text { (years) }\end{array}$ & Ethnicity & $\begin{array}{l}\text { Mean ALT }(\mathrm{U} / \mathrm{L}) \\
\text { (pre treatment) }\end{array}$ & $\begin{array}{l}\text { Viral load }(\mathrm{IU} / \mathrm{ml}) \text {, } \\
\text { pre treatment }\end{array}$ & $\begin{array}{l}\text { 3-month Treatment with } \\
\text { Tenofovir-stopped at delivery }\end{array}$ & $\begin{array}{l}\text { Mean ALT (U/L) } \\
\text { (post treatment) }\end{array}$ & $\begin{array}{l}\text { Viral load-after } \\
3 \text { months }\end{array}$ \\
\hline 1 & 29 & Chinese & 20 & $2.15 \times 10^{8}$ & Stopped 6 days before & 20 & 4 log drop \\
\hline 2 & 24 & African & 16 & $4.6 \times 10^{7}$ & Yes & 70 & 2 log drop \\
\hline 3 & 40 & Afghani & 24 & $1.4 \times 10^{7}$ & Yes & 88 & None recorded \\
\hline 4 & 34 & Asian & 35 & $>1.7 \times 10^{8}$ & Continued after birth & 55 & 6 log drop \\
\hline 5 & 22 & Chinese & 23 & $9.2 \times 10^{7}$ & Yes & 98 & None recorded \\
\hline
\end{tabular}

one stopped 6 days before birth. 1 mother continued after delivery due to increased ALT during treatment with ultrasound evidence of liver disease. There were no reported adverse effects. During or at the end of treatment four patients had rises in ALT ( $>1-2$ ULN) but no jaundice or hepatic decompensation. All the babies were born healthy and received immunoglobulin and vaccination.

Conclusion This small series demonstrates the safety of tenofovir in the last trimester of pregnancy. Small increases in ALT were seen which could be due to pregnancy, the initiation or discontinuation of tenofovir. It is necessary to assess the stage of liver disease to guide the treatment strategy after birth, although this is not always feasible in pregnancy. The timing of tenofovir discontinuation is determined by breastfeeding. We recommended that breastfeeding should start $24 \mathrm{~h}$ after treatment cessation, although there is not an evidence base to support this. Long-term prospective studies are indicated to confirm efficacy, safety and to determine optimal discontinuation strategies in relation to breastfeeding.

Competing interests None declared.

\section{PMO-150 SECOND HARMONIC GENERATION MICROSCOPY OF COLLAGEN AND EVALUATION OF LIVER FIBROSIS IN CHRONIC HEPATITIS C (CHC) INFECTION}

doi:10.1136/gutjnl-2012-302514b.150

${ }^{1} \mathrm{G}$ E Dolman, ${ }^{*} \mathrm{D}$ Sevrain, ${ }^{3} \mathrm{C}$ Odin, ${ }^{2} \mathrm{Y}$ Le Grand, ${ }^{4} \mathrm{~A} M$ Zaitoun, ${ }^{1,5} \mathrm{~W}$ L Irving, ${ }^{1}$ I N Guha. ${ }^{1}$ NIHR BRU NDDC, University of Nottingham, Nottingham, UK; ${ }^{2}$ Laboratoire de Spectrométrie et Optique Laser, Université de Bretagne Occidentale, Brest, France; ${ }^{3}$ Institut de Physique de Rennes, Université de Rennes 1, Rennes, France; ${ }^{4}$ Department of Histopathology, Nottingham University Hospitals, Nottingham, UK; ${ }^{5}$ School of Molecular Medical Sciences, University of Nottingham, Nottingham, UK

Introduction There is an urgent need to create tools to quantify collagen in liver fibrosis to facilitate stratification of disease and development of anti-fibrotic agents. Multiphoton microscopy enables imaging of unstained biopsies using endogenous sources of non-linear signals such as Two-Photon Excitation Fluorescence (TPEF) and Second Harmonic Generation (SHG). SHG allows specific detection of non-centrosymmetric structures such as fibrillar collagen, mainly type I. The SHG score is a measure of relative collagen area and is obtained by post-acquisition SHG/TPEF image processing. We have assessed the ability of our method to quantify collagen in advanced fibrosis due to $\mathrm{CHC}$, with respect to Ishak stage (IS).

Methods Biopsies from patients with advanced fibrosis (IS $\geq 3$ ) were selected from 1 centre in the Trent Study of Patients with Hepatitis C Virus, a prospective cohort study formed in 1991. Index biopsies prior to 2008 were selected and notes reviewed for subsequent liver related outcomes (LRO). LRO was defined as variceal bleed, ascites, encephalopathy, HCC or liver related death. SHG was measured on $4 \mu \mathrm{m}$ FFPE sections. A mask of the biopsy area was created with TPEF. Image processing was performed by two independent researchers, blinded to Ishak stage, using in-house macros and each using different software (Image J \& Matlab). PASW 17.0 was used for statistical analysis.

Results The SHG score was acquired in 58 of 83 biopsies (66\%). 25 were excluded due to signal artefact from paraffin, obscuring SHG signal from collagen. There was no significant difference in scoring by two researchers $(p<0.001)$. The median SHG score was $15.96 \%$ (IOR 11.3-21.3\%). Abstract PMO-150 figure 1 shows the median SHG score for each IS. SHG signal increased with disease severity (IS3:10.1\%; IS4:14.1\%; IS5:14.1\%; IS6:21.2\%). LRO occurred in 15 patients after a median of 57 months post-biopsy. The mean SHG score at index biopsy was $19.1 \%$ in those with, and $16.6 \%$ in those without subsequent LRO (non-significant difference, $\mathrm{p}>0.05$ ).

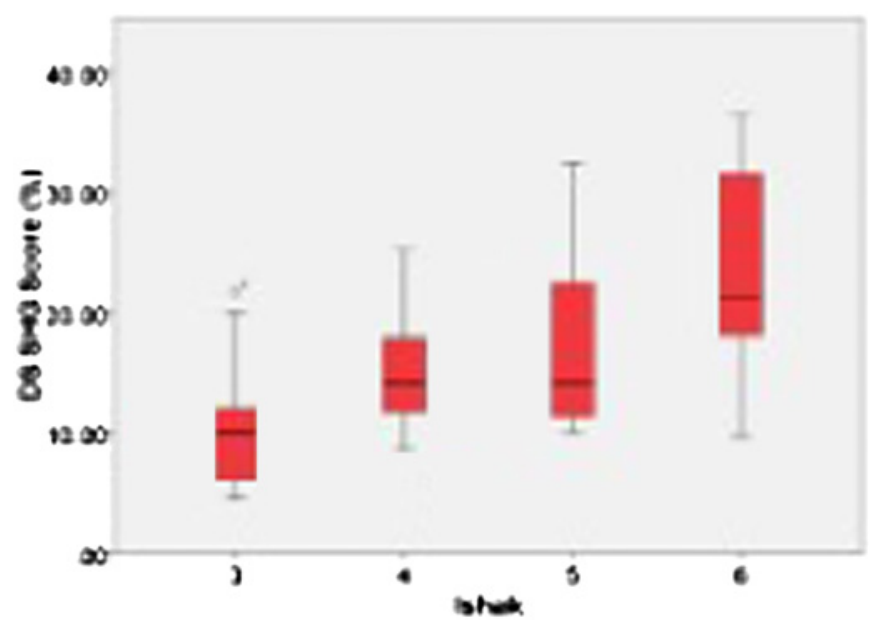

Abstract PM0-150 Figure 1

Conclusion SHG has proved to be a valuable method of quantifying collagen in liver fibrosis and does not require standard histochemical stains. Further development of this quantitative measure may result in a tool to assess response to anti-fibrotic therapy and progression to clinical endpoints.

Competing interests None declared.

\section{REFERENCES}

1. Gailhouste $\mathbf{L}$, et al. Fibrillar collagen scoring by second harmonic microscopy: A new tool in the assessment of liver fibrosis. J Hep 2010;52:398-406.

2. Guilbert $\mathbf{T}$, et al. A robust collagen scoring method for human liver fibrosis by second harmonic microscopy. Opt Expr 2010;18:25794-807.

\section{PM0-151 EXCELLENT DISEASE FREE AND OVERALL SURVIVAL RATES AFTER LONG TERM FOLLOW-UP OF A COHORT OF INJECTING DRUG USERS TREATED FOR HCV}

doi:10.1136/gutjnl-2012-302514b.151

${ }^{1} \mathrm{H}$ Lewis, ${ }^{*}{ }^{2} \mathrm{M}$ Wilkinson, ${ }^{2} \mathrm{~J}$ Dalton, ${ }^{2} \mathrm{H}$ Gardner, ${ }^{3} \mathrm{~J}$ Hothi, ${ }^{3} \mathrm{~N}$ lbrahim, ${ }^{2} \mathrm{~K}$ King, ${ }^{3} \mathrm{M}$ Mirza, ${ }^{2} \mathrm{~A}$ Tippett, ${ }^{2} \mathrm{~J}$ Turton, ${ }^{2} \mathrm{C}$ Woods, ${ }^{2} \mathrm{~S}$ Wynne, ${ }^{4} \mathrm{R}$ Igbe, ${ }^{1} \mathrm{G}$ R Foster. ${ }^{1}$ The Liver Unit, Queen Mary University of London, London, UK; ${ }^{2}$ Specialist Addiction Services, East London NHS Foundation Trust, London, UK; ${ }^{3}$ Barts and the London School of Medicine and Dentistry, London, UK; ${ }^{4}$ University of Bristol Medical School, Bristol, UK

Introduction Hepatitis C virus (HCV) is common in injecting drug users (IDU's), but $<10 \%$ of those known to be infected are 